\title{
Correlations between major risk factors and closely related Mycobacterium tuberculosis isolates grouped by three current genotyping procedures: a population-based study in northeast Mexico
}

\author{
Katia Peñuelas-Urquides ${ }^{1,2}$, Herminia Guadalupe Martínez-Rodríguez ${ }^{2}$, José Antonio Enciso-Moreno ${ }^{3}$, \\ Gloria María Molina-Salinas, ${ }^{1,4}$, Beatriz Silva-Ramírez¹, Gerardo Raymundo Padilla-Rivas², \\ Lucio Vera-Cabrera ${ }^{5}$, Víctor Manuel Torres-de-la-Cruz', Yazmin Berenice Martínez-Martínez², \\ Jorge Luis Ortega-García ${ }^{2}$, Elsa Nancy Garza-Treviño², Leonor Enciso-Moreno', \\ Odila Saucedo-Cárdenas', Pola Becerril-Montes', Salvador Said-Fernández ${ }^{1,2 /+}$
}

\begin{abstract}
'División de Biología Celular y Molecular, Centro de Investigación Biomédica del Noreste ${ }^{3}$ Unidad de Investigación Médica de Zacatecas, Instituto Mexicano del Seguro Social, Zacatecas, ZC, México ²Departamento de Bioquímica y Medicina Molecular ${ }^{5}$ Laboratorio Interdisciplinario de Investigación Dermatológica, Servicio de Dermatología, Hospital Universitario,

Facultad de Medicina, Universidad Autónoma de Nuevo León, Monterrey, NL, México ${ }^{4}$ Unidad de Investigación Médica de Yucatán, Unidad de Medicina de Alta Especialidad, Centro Médico Nacional Lic Ignacio García Téllez, Mérida, YN, México
\end{abstract}

The characteristics of tuberculosis (TB) patients related to a chain of recent TB transmissions were investigated. Mycobacterium tuberculosis (MTB) isolates (120) were genotyped using the restriction fragment length polymorphism-IS6110 (R), spacer oligotyping (S) and mycobacterial interspersed repetitive units-variable number of tandem repeats $(M)$ methods. The MTB isolates were clustered and the clusters were grouped according to the similarities of their genotypes. Spearman's rank correlation coefficients between the groups of MTB isolates with similar genotypes and those patient characteristics indicating a risk for a pulmonary TB (PTB) chain transmission were analysed. The isolates showing similar genotypes were distributed as follows: SMR (5\%), SM (12.5\%), SR (1.67\%), MR $(0 \%), S(46.67 \%), M(5 \%)$ and $R(0 \%)$. The remaining 35 cases were orphans. SMR exhibited a significant correlation $(p<0.05)$ with visits to clinics, municipalities and comorbidities (primarily diabetes mellitus). S correlated with drug consumption and $M$ with comorbidities. SMR is needed to identify a social network in metropolitan areas for PTB transmission and $S$ and $M$ are able to detect risk factors as secondary components of a transmission chain of TB.

Key words: Mycobacterium tuberculosis - MTB - genotyping - risk factors - tuberculosis transmission - population-based study

The research methods for pulmonary tuberculosis (PTB) transmission have been refined in communitybased studies. Within a target population, patients infected by isolates with identical DNA genotypes are assumed to be part of a PTB-transmission chain. Clustering is used as a proxy for recent transmission (Teeter et al. 2013). Population target-directed surveys performed to find TB micro-epidemics within specific groups of individuals have given excellent results in identifying household clusters (Verver et al. 2004, Park et al. 2008) or larger well-identified social networks (Quitugua et al. 2002, Clark et al. 2006, Supply et al. 2006, Oelemann et al. 2007, Jimenez-Corona et al. 2009). In addition, universal genotyping is a valuable tool to identify unsuspected recent PTB transmissions and previously unrecognised sites of transmission (Malakmadze et al.

doi: 10.1590/0074-0276130550

Financial support: FONSEC-SALUD, CONACYT-Mexico

(SALUD-2004-C01-62)

KP-U was supported by a fellowship from CONACYT-Mexico. KP-U, HGM-R, GMM-S and SS-F contributed equally to this work. SS-F current address: Centro de Investigación Biomédica del Noreste, Instituto Mexicano del Seguro Social, Zacatecas, ZC, México + Corresponding author: salvador.said@gmail.com

Received 25 November 2013

Accepted 6 August 2014
2005). The above-mentioned surveys are frequently performed in small communities and well-delimited zones and when PTB control in large cities requires the identification of the factors favouring a recent chain of PTB transmission, finding a common cause of PTB transmission is typically uncertain and very difficult (Pfyffer et al. 1998). Therefore, alternative approaches are required (Cook 2004). Before this study was conducted, we considered the following three facts: (i) if only one set of genetic markers was chosen to perform a population-based study, only a fraction or no Mycobacterium tuberculosis (MTB) isolates with identical markers could be directly related to the major causative factor of a transmission chain of TB, improving the discriminatory power of the genotyping procedure is needed, (ii) selecting the factors primarily related to a transmission chain of TB is crucial and (iii) a reliable connection between the genotyping results and those factors most strongly connected to recent events involved in TB transmission is required. Regarding the first issue, using a combination of two genotyping techniques to improve the discriminatory power of genotyping methods has been proposed. It has been noted that even two methods could not be sufficiently discriminative (Gori et al. 2005a). Other researchers have proposed using three combined genotyping methods to increase the probability of finding clusters of the characteristics of TB patients that are considered to be 
possible facilitating factors of PTB transmission. These characteristics have been divided into social networks, specifically crowded places where people frequently remain a long time (Cook et al. 2007) and risk factors such as the consumption of drugs, comorbidities, resistance to anti-tubercular drugs (Davies 2005) and indoor air pollution (Narasimhan et al. 2013). The third prerequisite for our investigation was to select a good method of finding a strong relationship between the MTB genotypes and the PTB patient characteristics. Thus, we hypothesised that if a statistical correlation between groups of isolates showing similar genotypes and peril factors were found, identifying micro-epidemics and the causes of a recent PTB transmission chain could be possible. We selected three of the most recognised methods used in molecular epidemiological studies of TB. These methods were restriction fragment length polymorphism (RFLP)-IS6110 (van Soolingen et al. 2001), spoligotyping (spacer oligotyping) (de la Salmonière et al. 1997) and mycobacterial interspersed repetitive units-variable number tandem repeats (MIRU-VNTR) (Cowan et al. 2002, Supply et al. 2006). Each of these procedures employs a defined set of MTB genetic markers to perform epidemiological studies. The percentages of similitude obtained with the marker sets determined with spoligotyping, MIRU-VNTR and RFLP-IS6110 are reproducible and globally comparable (Frothingham \& Meeker-O'Connell 1998, Cowan et al. 2005, Gori et al. 2005b, Supply et al. 2006).

This survey was performed in Nuevo León, Mexico. The metropolitan area of Monterrey (MAM) is an industrialised setting comprising nine municipalities (Apodaca, García, San Pedro Garza García, General Escobedo, Guadalupe, Monterrey, San Nicolás de los Garza and Santa Catarina). The MAM has a population of 4.2 million people (GENL 2014) and most of the population of Nuevo León (88\%) is in the MAM (GENL 2014). In 2012, 15,858 new cases of PTB were diagnosed in Mexico [rate $($ cases $/ 100,000$ inhabitants) $=17.4]$. Nuevo León reported an incidence rate that was $33.6 \%$ higher than the national rate $(1,074$ new cases; rate $=30.8)($ SS/México 2012).

In this study, we investigated the following inquiries: (i) how are MTB isolates organised into clusters and groups of clusters by applying the three aforementioned genotyping methods?, (ii) which clusters or groups of clusters were most strongly related to social networks or risk factors? and (iii) which PTB patient characteristics could cause the recent PTB transmission?

\section{PATIENTS, MATERIALS AND METHODS}

Target population - The target population consisted of 120 TB patients living in the MAM who were ensured by the Mexican Institute of Social Security (IMSS 2014). The IMSS provides health care for $83.5 \%$ of the patients in Nuevo León. During a 16-month period, all patients who visited the units of familiar medicine of the MAM with symptoms suggestive of PTB [268 (100\% of the suspicious cases in the MAM in the care of the IMSS)] were included in this study. A total of 134 patients had MTB-positive sputum samples and 120 of these patients agreed to participate in this study. The study group was composed of $64 \%$ men and $36 \%$ women between the ages of 13-84 years (median $=49$ years). The range of ages was 18-68 years and the time of residence in the MAM ranged from less than one year to 68 years (mean \pm standard deviation $=34.06 \pm 16.03$ years). The participants presented clear symptoms of PTB (WHO 2014) and acidfast bacilli (AFB) in their sputum samples. PTB patients attended their respective family medicine clinics or their zone hospitals during the study. In these facilities, the patients were diagnosed by a pulmonologist or epidemiologist. AFB were detected and reported by a chemist working in the clinical laboratory of each medical facility.

Collection of data regarding potential TB risk factors - The collection of epidemiological data and the isolation, MTB typing and genotyping were performed in the Northeast Biomedical Research Centre (CIBIN) of the IMSS. The patients with a clinical diagnosis of PTB signed an informed consent form and answered a questionnaire to provide appropriate information regarding the factors that could favour TB transmission (such as crowded places frequented by the PTB patients). Familial contacts and human immunodeficiency virus/acquired immune deficiency syndrome status were sought and correlated with the clusters; additionally, groups of clusters were analysed, but because the data were negative, these results are not presented in this article.

Social networks and risk factors - The elements of social networks analysed in this work were family medical clinics, zonal general hospitals, municipalities and familial contacts. The risk factors examined were comorbidities, patterns of resistance or sensitivity to first line anti-tubercular drugs, occupation and drug consumption (alcoholism, tobacco use and psychotropic substance abuse).

Control MTB strain - The MTB H37Rv strain (American Type Culture Collection, catalogue 27294) was included as an internal genotyping control.

MTB isolates - Each participant donated up to three sputum samples from which mycobacteria were isolated and typified. Immediately after collection, the samples were transported to our laboratory in the CIBIN, decontaminated and the bacteria were concentrated by centrifugation. A smear from every sputum sample was prepared and stained using the Ziehl-Neelsen method and AFB were microscopically examined (Ellis \& Zabrowarny 1993). Each of these samples was inoculated onto Lowenstein-Jensen (LJ) slants (Becton Dickinson, USA) and incubated in a $5 \% \mathrm{CO}_{2}$ atmosphere at $37^{\circ} \mathrm{C}$ for two-five weeks. Slants with typical MTB colonies were typified (Kent \& Kubica 1985, Balandrano-Campos et al. 1996) and stored at $-70^{\circ} \mathrm{C}$ until use. One MTB isolate per patient was included in this study.

Recovery of frozen isolates - The frozen MTB isolates were thawed at $-20^{\circ} \mathrm{C}$ overnight and then at $4^{\circ} \mathrm{C}$ for 3-4 h. Mycobacteria were inoculated on LJ slants and incubated at $37^{\circ} \mathrm{C}$ until colonies were clearly visible.

Drug sensitivity tests for first-line anti-MTB drugs - The tests were performed with a Bactec 460 radiometric system (Siddiqi 1996). The assayed drugs were isoniazid (INH) $(0.1 \mathrm{~g} / \mathrm{mL})$, streptomycin $(2.0 \mathrm{~g} / \mathrm{mL})$, 
rifampicin (RIF) $(2.0 \mathrm{~g} / \mathrm{mL})$, ethambutol $(2.5 \mathrm{~g} / \mathrm{mL})$ and pyrazinamide $(100 \mathrm{mg} / \mathrm{mL})$. All anti-TB drugs were purchased from Becton Dickinson.

Extraction of MTB DNA - Under aseptic conditions, two loops of mycobacteria colonies were transferred to a glass test tube containing $2.5 \mathrm{~mL}$ of Tris-EDTA buffer [10 mM Tris/HCl pH 8) (Amresco, USA) and $1.0 \mathrm{mM}$ EDTA (Promega, USA)] and five-six glass beads. The suspension was homogenised using a vortex and a 0.5 $\mathrm{mL}$ aliquot was transferred to a $1.5-\mathrm{mL}$ capped conical polypropylene tube (Eppendorf, Germany) and inactivated in an $80^{\circ} \mathrm{C}$ water bath (Terlab M40, Mexico) for 50 min. DNA was extracted from mycobacteria according to the CTAB (hexadecyltrimethyl-ammonium bromide) method (van Soolingen et al. 2001).

Genotyping procedures - MTB spoligotypes were analysed according to Kamerbeek et al. (1997) using a commercial kit (Isogen Life Science, the Netherlands). RFLP-IS6110 analyses were performed according to van Embden et al. (1993) and MIRU-VNTR analyses were performed according to Cowan et al. (2002) and Supply et al. (2006). To identify the MIRU and VNTR, the following 15 loci were analysed: MIRU 4, 10, 16, 26, 31 and 40 (Cowan et al. 2002) as well as Mtub 04, ETR C, ETR A, QUB 11b, Mtub21, QUB26, Mtub30, Mtub39 and QUB4156 (Supply et al. 2006).

Analysis of genotyping data - Based on the findings of Lindquist et al. (2013), we defined clusters as those PTB cases with indistinguishable MTB genotypes. The spoligotypes were converted to their corresponding octal codes as described by Dale et al. (2001) and clusters and unique patterns were identified using SPSS software, v.10.0. The RFLP-IS6110 data were analysed with BioNumerics software, v.2.0 (Applied Maths, Belgium) using the unweighted pair group method with an arithmetical mean and Dice's coefficient. The running differences in the gels were normalised using the relative position of the $\lambda /$ Hind III and $\varphi$ X174/Hae III molecular weight markers (Sigma-Aldrich) using BioNumerics software. To determine the best tolerance, a DNA sample from the reference strain $\mathrm{H} 37 \mathrm{Rv}$ was included in each assay. When the alignments of all of the reference RFLP-IS6110 patterns from all the agarose gels matched, the tolerance value was set at $1.9 \%$. The genotypes were considered identical according to the results from the analyses performed by the BioNumerics program. Because RFLP-IS6110 codes have not been previously described, we designed a code using the relative migration of each IS6110 band ( $\left.\mathrm{R}_{\mathrm{f}}\right)$ of every MTB isolate DNA sample (Fig. 1). The description of the RFLPIS6110 codes is as follows: the RFLP-IS6110 codes have two arms of numbers, separated by a dot. The left arm is composed of one or two digits and includes information regarding the number of bands found in each MTB isolate. The right arm contains the $\mathrm{R}_{\mathrm{f}}$ of each DNA band with an IS-6110 element. Each $R_{f}$ is represented by three numbers. From left to right, the $\mathrm{R}_{\mathrm{f}}$ values were placed in descending order of DNA-molecular weight. The $R_{f}$ values were calculated by dividing the distance between
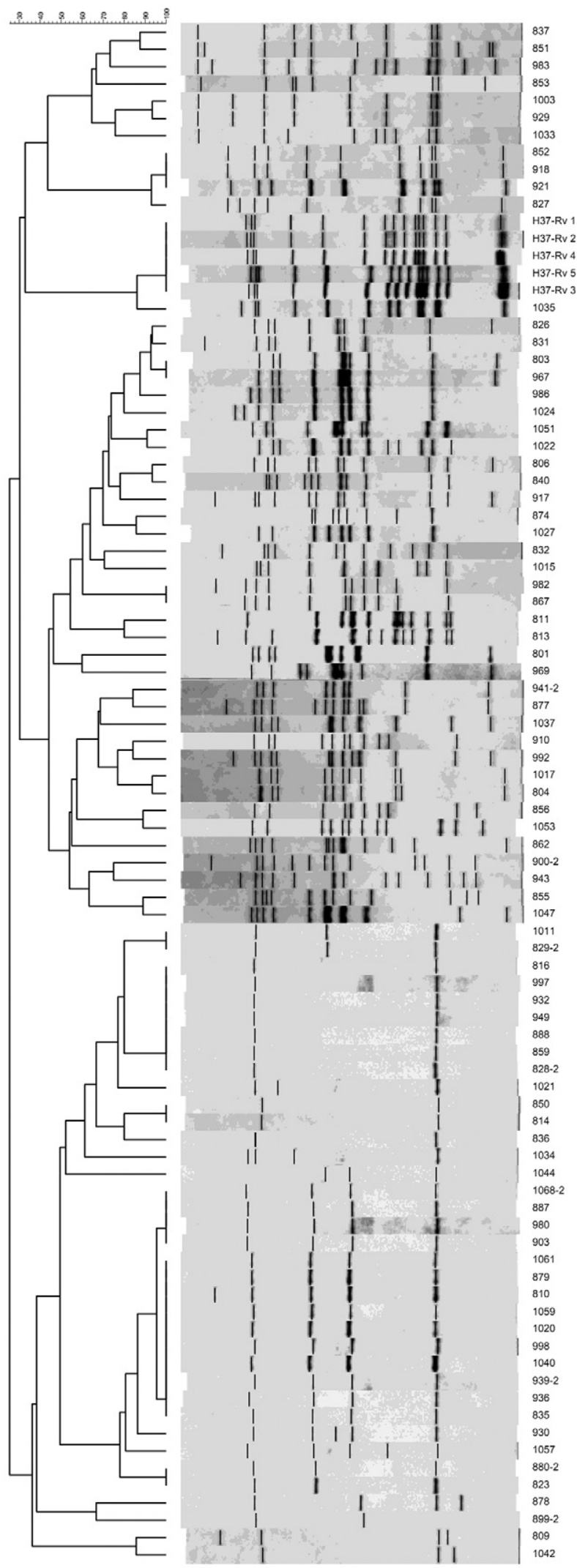

Fig. 1: restriction fragment length polymorphism (RFLP)-IS6110 diagram and dendrogram. These were generated by the BioNumerics software and show the relationships of clusters and groups of clusters using the RFLP-IS6110 method exclusively. Numbers on the right side are case-identifiers. 
the origin and front of the electrophoresis by the distance travelled by each IS6110-band and multiplying by $1 \times 10^{3}$. The MIRU-VNTR patterns were analysed with Microsoft Excel 2002 software (Microsoft Co, USA). The corresponding codes were constructed according to Cowan et al. (2002) and Supply et al. (2006). The cluster groups with comparable codes were named as follows to differentiate the clusters from the genotyping methods: spoligotypes, MIRU-VNTR and RFLP-IS6110, SMR, spoligotypes and RFLP-IS6110, SR, spoligotypes and MIRU-VNTR, SM, MIRU-VNTR and RFLP-IS6110, MR, spoligotypes, S, RFLP-IS6110, R, and MIRU-VNTR, M. The methods are referred to by their corresponding shortened names (spoligotyping, MIRU-VNTR and RFLP-IS6110).

Venn diagram - The Venn diagram describes the metrics by which the 120 MTB isolates were organised using spoligotyping, MIRU-VNTR and RFLP-IS6110. The diagram was constructed using PowerPoint software for Windows 7 (Microsoft Co) with the data depicted in Table I.

Statistics - The significance $(\mathrm{p}=0.05)$ for correlation between the aforementioned cluster-groups and the PTB characteristics was calculated by Spearman's $\sigma$. Statistical correlation referred to the relationships that involved the dependence of code-set belonging to each MTB cluster group having comparable genetic codes and each PTB patient characteristic.

Ethics - This protocol represented a minor risk for TB patients and was authorised by the Scientific and Ethical Committee of the CIBIN/IMSS (protocol R-2005-1908-2).

\section{RESULTS}

Genotyping - RFLP-IS6110 patterns - Fig. 1 shows the RFLP-IS6110 patterns and dendrogram of the 120 PTB clinical isolates. The Venn diagram (Fig. 2) describes the metrics by which the 120 MTB isolates were organised using spoligotyping, MIRU-VNTR and RFLP-IS6110. While $70.83 \%$ (85) of the isolates were clustered, $29.17 \%$ (35) of the isolates (unique or orphan cases) were not clustered by any genotyping method. The clusters constituted the following groups with respect to the $120 \mathrm{MTB}$ isolates: SMR, 5\% (6 isolates), SM, 12.50\% (15 isolates), SR, $1.60 \%$ (2 isolates), M, 5\% (6 isolates) and S, 46.67\% (56 isolates). MR and $\mathrm{R}$ clusters were not observed. Supplementary data, Table I shows each case identified by the number assigned by our laboratory and its corresponding S, M or R code. Supplementary data, Table II retains the identical organisation of the MTB cases as clusters and groups of clusters, as in Supplementary data, Table I. Supplementary data, Table II depicts the factors that could favour PTB transmission in our target population. Five groups were formed with comparable codes for spoligotyping, MIRU-VNTR and RFLP-IS6110 (SMR), a combination of two codes (SR and SM) or only one (S and M). Group six was formed by orphan cases. Additionally, Supplementary data, Table II shows that the variables with the highest frequencies were first (family medicine clinic 35) and second level medical facilities (zonal general hospitals 4 and 17), municipalities (Guadalupe and Monterrey), comorbidities (diabetes mellitus type 2), oc- cupation (car painting, mining and industrial production), multidrug resistance (to at least RIF and INH) and drug consumption (tobacco use and alcoholism).

Association of cluster groups with situations favouring TB transmission - Tables I, II show the association of cluster groups with crowded places frequented by PTB patients and risk factors. SMR presented a significant correlation with family medicine clinics, municipalities, comorbidities and drug consumption. SR and factors favouring MTB transmission were not calculated because the number of cases was insufficient. M exhibited correlation with comorbidity. No relationship was found between a cluster group and members of the same family or neighbours.

\section{DISCUSSION}

We showed that a combination of RFLP-IS6110, MIRU-VNTR and spoligotyping is essential to identify MTB clusters, to group the clusters and to discard orphan cases. Using these data, we investigated how social networks and risk factors correlated with the cluster groups (Glynn et al. 2002, Hasan et al. 2006, Narasimhan et al. 2013). SMR was the only group that correlated with two of the three elements of social networks and with two of the four risk factors considered in this study. Our data strongly suggest that when TB surveys are performed in a metropolis, such as the MAM, the more markers that are considered in performing a correlation analysis with risk factors, the more reliable the connection with a PTB epidemic focus would be.

The factors that correlated with SMR substantiated a recent MTB transmission. Regarding social networks (family medicine clinics, primary clinics and municipalities), patients typically remain a long time in crowded waiting rooms. Clinic waiting rooms are closed environments with recirculated air, in which bacillipherous patients are seated by individuals without PTB. During

\section{TABLE I}

Association of cluster-groups and social networks Level of medical attention

\begin{tabular}{cc}
\hline Clinics of & Zonal \\
familiar medicine & general hospitals
\end{tabular} Municipality

\begin{tabular}{lccc}
\cline { 2 - 4 } Group $^{a}$ & \multicolumn{3}{c}{ Spearman's correlation } \\
\hline SMR & $\mathbf{0 . 0 3 3}$ & 0.166 & 0.013 \\
SR & $\mathrm{NC}^{b}$ & $\mathrm{NC}$ & $\mathrm{NC}$ \\
$\mathrm{SM}$ & 0.677 & 0.256 & 0.380 \\
$\mathrm{~S}$ & 0.078 & 0.105 & 0.316 \\
$\mathrm{M}$ & 0.779 & 0.559 & 0.261 \\
\hline
\end{tabular}

$a$ : groups of clusters having comparable codes; $b$ : not computable (NC) because these groups were constituted just by one cluster having two cases. Capitals correspond to groups of clusters showing comparable codes of spoligotyping (S), mycobacterial interspersed repetitive units-variable number tandem repeats (M) or restriction fragment length polymorphism-IS6110 (R). Bold numbers indicate statistical significance $(\mathrm{p} \leq 0.05)$. 
TABLE II

Association of cluster-groups with risk factors

\begin{tabular}{|c|c|c|c|c|}
\hline \multirow[b]{2}{*}{ Group } & Comorbidity & Pattern of drug resistance & Occupation & Drug consumption \\
\hline & \multicolumn{4}{|c|}{ Spearman's correlation } \\
\hline SMR & 0.047 & 0.643 & 1.000 & 0.012 \\
\hline SR & $\mathrm{NC}^{a}$ & $\mathrm{NC}$ & $\mathrm{NC}$ & $\mathrm{NC}$ \\
\hline SM & 0.381 & 0.278 & 0.234 & 0.531 \\
\hline S & 0.196 & 0.400 & 0.067 & 0.271 \\
\hline M & 0.047 & 0.492 & 1.000 & 0.391 \\
\hline
\end{tabular}

$a$ : not computable (NC) because these groups were constituted just by one cluster having two cases. Capitals correspond to groups of clusters showing comparable codes of spoligotyping $(\mathrm{S})$, mycobacterial interspersed repetitive units-variable number tandem repeats $(\mathrm{M})$ or restriction fragment length polymorphism-IS6110 (R). Bold numbers indicate statistical significance $(\mathrm{p} \leq 0.05)$.

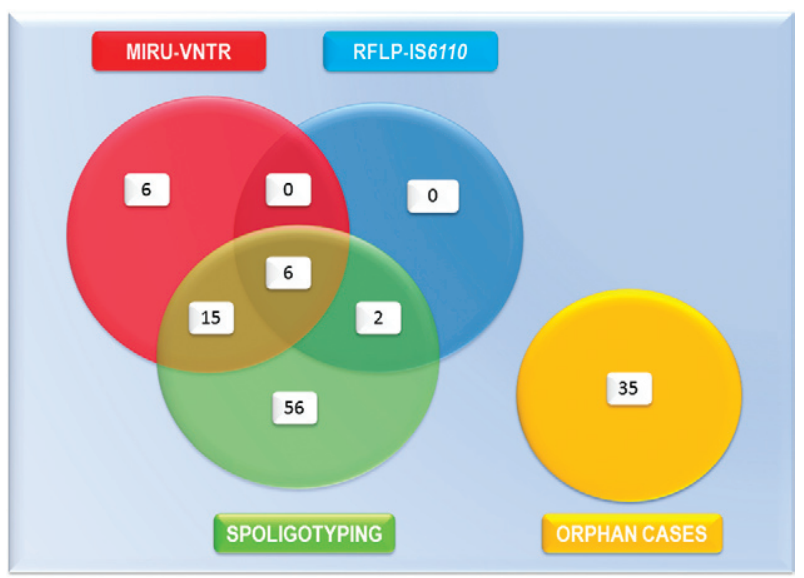

Fig. 2: Venn diagram. Schematic representation by which the 120 Mycobacterium tuberculosis-isolates included in this study were organised by spoligotyping, mycobacterial interspersed repetitive unitsvariable number tandem repeats (MIRU-VNTR) and the conventional restriction fragment length polymorphism (RFLP)-IS6110 analysis. Orphan cases were no clustered by any genotyping method.

standard treatment, patients repeat this type of visit several times. No correlation was observed between SMR and zonal general hospitals, possibly because TB patients are treated in family medicine clinics by an epidemiologist until the case of TB is cured or the patient is referred to a pulmonologist at a specialty hospital. Thus, the risk of PTB transmission in second level facilities is markedly reduced. PTB transmission throughout social networks has been previously reported; García-García et al. (2000) found an RFLP-IS6110 cluster that developed after PTB micro-epidemics occurred in a social network formed by assiduous clients attending clandestine bars. In addition to first level medical facilities, workers and housewives typically frequent the same crowded public places, such as schools, markets, stores, cinemas, churches or bars and are transported by urban buses. A significant proportion of our patients had diabetes or abused drugs. These factors are recognised as risk factors (Davies 2005) and we identified the correlations of diabetes and drug abuse with SMR.
The application of a combination of spoligotyping, MIRU-VNTR and RFLP-IS6110 and an analysis of Spearman's correlation of these genotypes with factors that could facilitate MTB transmission is required to discover new PTB micro-epidemics that are possible in a metropolitan population. Considering the increase in multidrug resistant and extended drug resistant MTB strains that threaten TB control worldwide (WHO 2014), the recent development of strains resistant to all first and second line anti-TB drugs, which have been identified as completely MTB resistant (totally drug-resistant-MTB) (Rowland 2012), could be useful for applying analyses such as this one to describe future TB surveys or potential epidemic foci of PTB.

\section{ACKNOWLEDGEMENTS}

To Arturo Vázquez-Guerrero, Karina T GonzálezRodríguez, Perla Idalia-Vázquez Hernández, July Angelly Arellanes-González, Fabiola Burciaga-Córdoba, Graciela Arelí López-Uriarte, Fabiola Saldívar-Garza, Sofía Nuñez-delaRosa, Mariana Ibarra-González, Liliana Rivadeneyra-Espinosa and Liliana Romero-Martínez, for performing the field-investigation during their social service, and to Drs Salvador Valdovinos Chávez, Patricia Pérez Cortes and Francisco F Fabela, for their official support during the development of this study.

\section{REFERENCES}

Balandrano-Campos S, Anzaldo-Flores G, Flores GPP, Betancourt-Morillo X 1996. Tuberculosis: manual de procedimientos de laboratorio, 18, Instituto Nacional de Referencia Epidemiológica/Secretaría de Agricultura, Ganadería y Desarrollo Rural, México DF, 15 pp.

Clark CM, Driver CR, Munsiff SS, Driscoll JR, Kreiswirth BN, Zhao B, Ebrahimzadeh A, Salfinger M, Piatek AS, Abdelwahab J 2006. Universal genotyping in tuberculosis control program, New York City, 2001-2003. Emerg Infect Dis 12: 719-724.

Cook VJ 2004. Social network analysis methods to characterize tuberculosis transmission patterns. B C Med J 46: 296.

Cook VJ, Sun SJ, Tapia J, Muth SQ, Arguello DF, Lewis BL, Rothenberg RB, McElroy PD 2007. Transmission network analysis in tuberculosis contact investigations. J Infect Dis 196: 1517-1527.

Cowan LS, Diem L, Monson T, Wand P, Temporado D, Oemig TV, Crawford JT 2005. Evaluation of a two-step approach for largescale, prospective genotyping of Mycobacterium tuberculosis isolates in the United States. J Clin Microbiol 43: 688-695. 
Cowan LS, Mosher L, Diem L, Massey JP, Crawford JT 2002. Variable-number tandem repeat typing of Mycobacterium tuberculosis isolates with low copy numbers of IS 6110 by using mycobacterial interspersed repetitive units. J Clin Microbiol 40: 1592-1602.

Dale JW, Brittain D, Cataldi AA, Cousins D, Crawford JT, Driscoll J, Heersma H, Lillebaek T, Quitugua T, Rastogi N, Skuce RA, Sola C, van Soolingen D, Vincent V 2001. Spacer oligonucleotide typing of bacteria of the Mycobacterium tuberculosis complex: recommendations for standardized nomenclature. Int J Tuberc Lung Dis 5: 216-219.

Davies PD 2005. Risk factors for tuberculosis. Monaldi Arch Chest Dis 63: 37-46.

de la Salmonière Y-OG, Li HM, Torrea G, Bunschoten A, van Embden J, Gicquel B 1997. Evaluation of spoligotyping in a study of the transmission of Mycobacterium tuberculosis. J Clin Microbiol 35: 2210-2214.

Ellis RC, Zabrowarny LA 1993. Safer staining method for acid-fast bacilli. J Clin Pathol 46: 559-560.

Frothingham R, Meeker-O’Connell WA 1998. Genetic diversity in the Mycobacterium tuberculosis complex based on variable numbers of tandem DNA repeats. Microbiology 144: 1189-1196.

Garcia-Garcia M, Palacios-Martinez M, Ponce-de-Leon A, Jimenez-Corona ME, Jimenez-Corona A, Balandrano-Campos S, Olivera-Diaz H, Valdespino-Gomez JL, Small PM 2000. The role of core groups in transmitting Mycobacterium tuberculosis in a high prevalence community in southern Mexico. Int J Tuberc Lung Dis 4: 12-17.

GENL - Gobierno del Estado de Nuevo León 2014. Estadísticas de población en Nuevo León. Available from: nl.gob.mx/?P=nl_ poblacion.

Glynn JR, Whiteley J, Bifani PJ, Kremer K, van Soolingen D 2002. Worldwide occurrence of Beijing/W strains of Mycobacterium tuberculosis: a systematic review. Emerg Infect Dis 8: 843-849.

Gori A, Bandera A, Marchetti G, Esposti AD, Catozzi L, Nardi GP, Gazzola L, Ferrario G, van Embden JDA, van Soolingen D, Moroni M, Franzetti F 2005a. Spoligotyping and Mycobacterium tuberculosis. Emerg Infect Dis 11: 1242-1248.

Gori A, Esposti AD, Bandera A, Mezzetti M, Sola C, Marchetti G, Ferrario G, Salerno F, Goyal M, Diaz R, Gazzola L, Codecasa L, Penati V, Rastogi N, Moroni M, Franzetti F 2005b. Comparison between spoligotyping and IS-6110 restriction fragment length polymorphisms in molecular genotyping analysis of Mycobacterium tuberculosis strains. Mol Cell Probes 19: 236-244.

Hasan Z, Tanveer M, Kanji A, Hasan Q, Ghebremichael S, Hasan R 2006. Spoligotyping of Mycobacterium tuberculosis isolates from Pakistan reveals predominance of central Asian strain 1 and Beijing isolates. J Clin Microbiol 44: 1763-1768.

IMSS - Instituto Mexicano del Seguro Social 2014. Población total por entidad federativa, sexo y grupos quinquenales de edad y su distribución según condición de derecho habiencia a servicios de salud e institución. Available from: imss.gob.mx/delegaciones/ nuevoleon/Documents/poblacion.pdf.

Jiménez-Corona ME, Garcia-Garcia L, de León AP, del Valle MB, Torres M, Quintero SC, Merino CP, Hernández SM, Gamboa RM, Sandino LJ, Cano-Arrellano B, Reyes LF, Hervert LPC, Baez-Saldaña R, Ferreira-Guerrero E, Sada E, Marquina B, Sifuentes-Osornio J 2009. Investigación sobre epidemiología convencional y molecular de tuberculosis en Orizaba, Veracruz 1955-2008. Salud Publica Mex 51 (Suppl. 3): 470-478.

Kamerbeek J, Schouls L, Kolk A, van Agterveld M, van Soolingen D, Kuijper S, Bunschoten A, Molhuizen H, Shaw R, Goyal M, van Embden J 1997. Simultaneous detection and strain differentiation of Mycobacterium tuberculosis for diagnosis and epidemiology. J Clin Microbiol 35: 907-914.

Kent PT, Kubica GP 1985. Public health micobacteriology: a guide for the level III laboratory, Department of Health and Human
Services/Public Health Service/Centers for Disease Control, Atlanta, 207 pp.

Lindquist S, Allen S, Field K, Ghosh S, Haddad MB, Narita M, Oren E 2013. Prioritizing tuberculosis clusters by genotype for public health action, Washington, USA. Emerg Infect Dis 19: 493-496.

Malakmadze N, González IM, Oemig T, Isiadinso I, Rembert D, McCauley MM, Wand P, Diem L, Cowan L, Palumbo GJ, Fraser M, Ijaz K 2005. Unsuspected recent transmission of tuberculosis among high-risk groups: implications of universal tuberculosis genotyping in its detection. Clin Infect Dis 40: 366-373.

Narasimhan P, Wood J, Macintyre CR, Mathai D 2013. Risk factors for tuberculosis. Pulm Med 2013: 828939.

Oelemann MC, Diel R, Vatin V, Haas W, Rusch-Gerdes S, Locht C, Niemann S, Supply P 2007. Assessment of an optimized mycobacterial interspersed repetitive-unit-variable-number tandemrepeat typing system combined with spoligotyping for population-based molecular epidemiology studies of tuberculosis. J Clin Microbiol 45: 691-697.

Park EJ, Kim Y-K, Bok JH, Lee YM, Kim KU, Uh S-t, Park Y-K 2008. Use of molecular identification analysis in a case of intra-familial transmission of tuberculosis. Tuberc Respir Dis (Seoul) 65: 512-516.

Pfyffer GE, Strassle A, Rose N, Wirth R, Brandli O, Shang H 1998. Transmission of tuberculosis in the metropolitan area of Zurich: a 3 year survey based on DNA fingerprinting. Eur Respir $J 11$ : 804-808.

Quitugua TN, Seaworth BJ, Weis SE, Taylor JP, Gillette JS, Rosas II, Jost Jr KCJ, Magee DM, Cox RA 2002. Transmission of drug-resistant tuberculosis in Texas and Mexico. J Clin Microbiol 40: 2716-2724.

Rowland K 2012. Totally drug-resistant TB emerges in India. Available from: nature.com/news/totally-drug-resistant-tb-emergesin-india-1.9797.

Siddiqui S 1996. BACTEC TB System. Product and procedure manual, Becton Dickinson, Sparks, 165 pp.

SS/México - Secretaría de Salud/México 2012. Situación actual de la tuberculosis en México, 2do Curso de Actualizacion en Tuberculosis Farmacorresistente, Centro Nacional de Programas Preventivos y Control de Enfermedades. Available from: es.slideshare. net/TbNuevoLeon/situacin-actual-de-la-tuberculosis-en-mxico\#.

Supply P, Allix C, Lesjean S, Cardoso-Oelemann M, Rüsch-Gerdes S, Willery E, Savine E, de Haas P, van Deutekom H, Roring S, Bifani P, Kurepina N, Kreiswirth B, Sola C, Rastogi N, Vatin V, Gutierrez MC, Fauville M, Niemann S, Skuce R, Kremer K, Locht C, van Soolingen D 2006. Proposal for standardization of optimized mycobacterial interspersed repetitive unit-variablenumber tandem repeat typing of Mycobacterium tuberculosis. $J$ Clin Microbiol 44: 4498-4510.

Teeter LD, Ha NP, Ma X, Wenger J, Cronin WA, Musser JM, Graviss EA 2013. Evaluation of large genotypic Mycobacterium tuberculosis clusters: contributions from remote and recent transmission 1. Tuberculosis (Edinb) 93 (Suppl.): S38-S46.

van Embden JD, Cave MD, Crawford JT, Dale JW, Eisenach KD, Gicquel B, Hermans P, Martin C, McAdam R, Shinnick TM 1993. Strain identification of Mycobacterium tuberculosis by DNA fingerprinting: recommendations for a standardized methodology. $J$ Clin Microbiol 31: 406-409.

van Soolingen D, de Haas PE, Kremer K 2001. Restriction fragment length polymorphism typing of mycobacteria. Methods Mol Med 54: 165-203.

Verver S, Warren RM, Munch Z, Richardson M, van der Spuy GD, Borgdorff MW, Behr MA, Beyers N, van Helden PD 2004. Proportion of tuberculosis transmission that takes place in households in a high-incidence area. Lancet 363: 212-214.

WHO - World Health Organization 2014. Tuberculosis (TB). Available from: who.int/topics/tuberculosis/en/). 